Arqueología y Sociedad,

№ 23, 2011

\title{
"Chachapuya" y "PuRUM": IDENTIDAd Y SIMBOLIZACIÓN ANCESTRAL DE UNA SOCIEDAD TARDÍA EN EL DEPARTAMENTO DE AMAZONAS
}

Jorge Luis Ruíz Barcellos*

\section{Resumen}

"En este territorio hombres y mujeres distintos a muchos lugares del Incario usan ropas de lana y en sus cabezas tienen sus llautos, dedicados al ganado, elaboran tapicería muy fina; tienen a Cuchaycuella como dios y creencia en las estrellas -chuquechinchay o imagen de un tigre, león o felino", así describen a los Chachapoyas los primeros historiógrafos (Cieza de León 1553; Albornoz 1570; Garciliso de la Vega 1609; Calancha 1638) - hoy, en gran parte todo ello persiste en los relatos y en la vida tradicional de jalquinos y utcubambinos del temple.

Algunos estudios históricos refieren que sería la administración cusqueña quienes habrían identificado de esta manera a la gente local, y que, incluso entre los siglos XVII y XVIII habría registros de más grupos poblacionales con nombres propios; sin embargo, la arqueología aún no ha logrado identificar materialmente esta diversidad de grupos. Chachapoyas sigue siendo entendido como un espacio territorial y cultural que abarcaría más de 90 mil $\mathrm{km}^{2}$ aproximadamente donde se desenvolvieron "ciudades", "centros poblados", lugares de religiosidad e infraestructura de conectividad y que hoy, muchos todavía de sus restos se encuentran ocultos o en silencio en los actuales departamentos de Amazonas, San Martín y La Libertad, e incluso en territorios colindantes con el actual Huánuco.

Debido a que en la actualidad existen abundantes estudios historiográficos de los Chachapoyas, es que hemos decidido retomar el tema explorando otras perspectivas, las cuales no siempre han sido muy bien fundamentadas y profundizadas. Un análisis estructural de la etnolingüística y de la simbolización que permanentemente poseen las grafías andinas, en este caso ubicadas en contextos nor andino y amazónicos, nos permiten observar nuevas acepciones de identidad, pero también de simbolización que deberán cambiar la forma de entender a los Chachapoyas en el contexto andino y nor amazónico.

Palabras clave

Chachapuya, Purum, incario, etnia, identidad, categorías, "no civilizados", transformación, movilidad, diluvio, simbolismo, mítico, tradición oral.

* Investigador de INCADS -Instituto Científico de Arqueología, Antropología, Turismo y Conservación para el Desarrollo Sustentable-, creado en 2010 mediante Título Registral N el N²010-00003570, partida registral № 11019997. Estamos desarrollando varios estudios e investigaciones que en adelante serán útiles para activar diversas actividades de desarrollo y fortalecimiento de la zona. Nuestras investigaciones en Amazonas han ocupado nuestro compromiso personal en más de 10 años, publicando algunas reflexiones de investigación como el presente artículo.

Correo electrónico: jl__barcellos@yahoo.es 


\begin{abstract}
"In this country men and women different from many parts of the Incas wear clothes of wool on their heads have their llauto dedicated to livestock, produce very fine upholstery; have Cuchaycuella as God and belief in the stars chuquechinchay or image of a tiger, lion or cat, "and described the Chachapoyas early historians (Cieza de León 1553; Albornoz 1570; Garciliso de la Vega 1609; Calancha 1638) - Today, largely persists in all the stories and the traditional life Utcubambinos of Jalquinos and hardening.

Some historical studies report that the administration would have identified those Cusqueña this way the local people, and even between the seventeenth and eighteenth centuries would have records of more population groups with names, but archeology has failed not only to identify materially the diversity of groups. Chachapoyas is still understood as a territorial and cultural space that would include more than 90 thousand $\mathrm{km}^{2}$, where they developed "cities" "population centers" places of religious and infrastructure and connectivity that today, many still their remains are hidden or silent in the current departments of Amazonas, San Martín and La Libertad, and even in areas adjacent to the current Huánuco.

Due to the nature historiographical only have until today known as the Chachapoyas that, we have decided to revisit the issue from observations from other perspectives, which have not been very well supported and deepened. A structural analysis of ethnolinguistic and symbolization that permanently possess the Andean photographs in this case located in the Andean and Amazonian normal contexts allow us to observe new senses of identity, but also symbolizing that should change the way we understand the identity of Chachapoyas (s) in the north Andean and Amazonian context.
\end{abstract}

\title{
Keywords
}

Chachapuya, Purum, incario, ethnicity, identity categories, "uncivilized", transformation, mobility, flood, symbolism, myth, oral tradition.

\section{Los Chachapoyas}

Los primeros historiógrafos del siglo XVI dan a conocer sobre la existencia de una importante región en el norte y extremo norte peruano, aquí habitaban "diversos grupos" con respecto a muchas otras del contexto Andino, así lo manifiestan el Inca Garcilaso de la Vega (1609), Pedro Cieza de León (1553), Guaman Poma de Ayala (1616) e incluso en los documentos del administrador inquisidor Albornoz (1570).

Los primigenios estudios etnohistóricos de la segunda mitad de siglo XX, referentes a la región, mencionan una serie de características que colocan a los cusqueños como los que habrian dado la denominación de Chachapoyas.

Los vestigios arqueológicos del actual territorio del departamento de Amazonas se encuentran presentes en $87,248.88 \mathrm{Km}^{2}$. Sus características ecológicas distinguen la existencia de matorrales y áreas de bosques bajos, con climas ecológicamente distintos a aquellos sitios arqueológicos ubicados entre los 1800 y 3,500 m.s.n.m. en contextos geográficos de Bosques Nubosos (Figura 1).

En este escenario histórico-arqueológico se ha traspuesto la presencia del Incario mimetizándose con las viejas formas locales, superando éste un territorio de $30,000 \mathrm{~km}^{2}$ aproximadamente; sus límites habrían sido por el noroeste y suroeste el Marañón; luego estarían los escenarios del valle de Utcubamba, Levanto, Sonche, Ventilla, Pomacochas en el norte, Rodríguez de Mendoza al este y en el extremo norte del departamento incluso hay informaciones sobre la interrelación del Incario con los grupos y etnias Awuajún y Wuampis. 


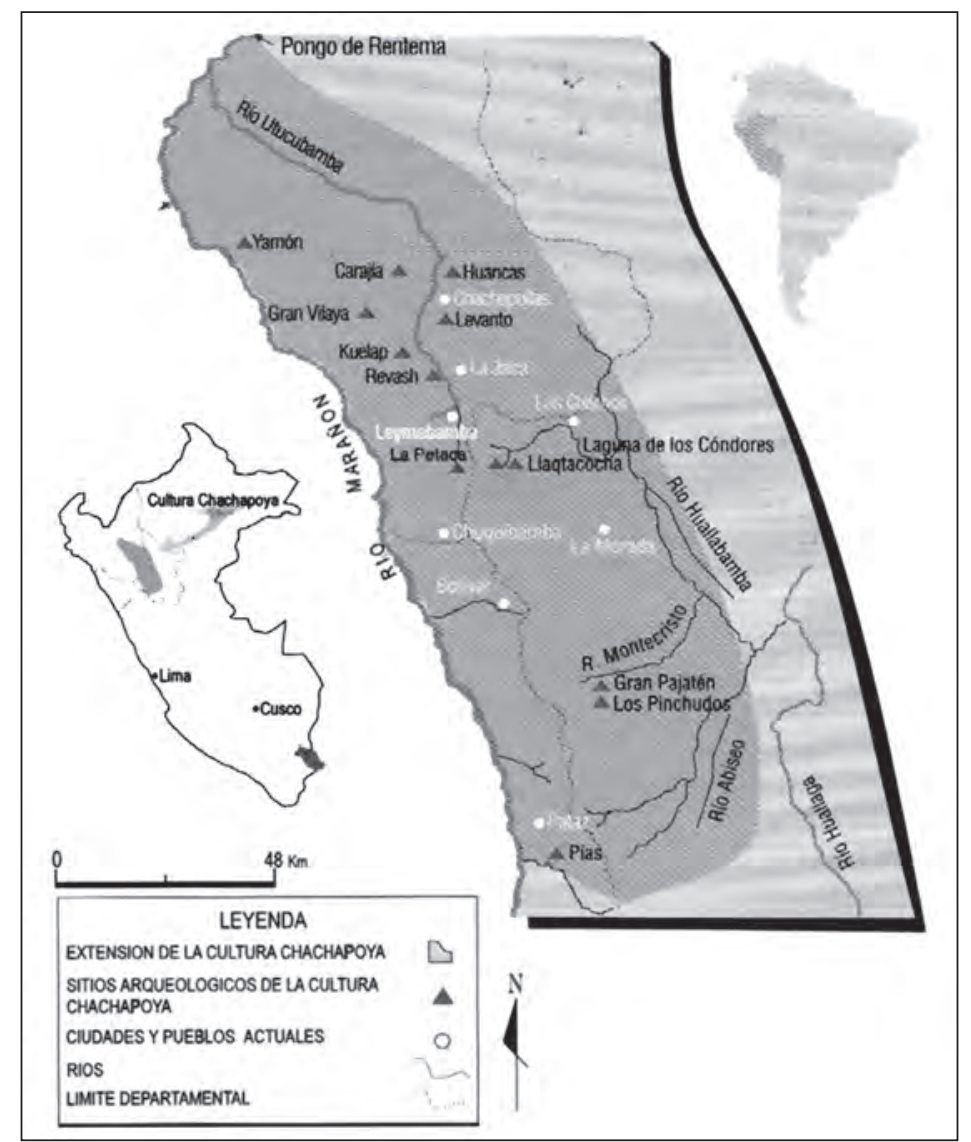

Figura 1: Mapa de ámbito del proceso cultural de los "Chachapoya (s)".

A. Von Hagen, 2000:9. Revista ICONOS, número 4.

Los centros residenciales más resaltantes durante la presencia Inca en la zona habrían sido Cochabamba, Chuquibamba, Leymebamba, Jalca Grande, Levanto y Ventilla, y Rodríguez de Mendoza, pero no refieren de otros centros de factura y organización local, así lo explican algunos documentos administrativos de la Colonia en Amazonas.

En ese sentido el Dr. Espinoza Soriano (1967) y Dra. I. Schjellerup (1976; 2005) han asumido que los Chachapoya se constituyeron una "provincia Inca" perteneciente a la región del Chinchaysuyo, según la distribución administrativa y política que el Incario impuso en el Tahuantinsuyo. En esta "provincia" con anterioridad habrían existido modelos de organización en Guarangas y Pachacas y que eso permitió la constitución del modelo de organización y admi- nistración en Hunos, posiblemente siendo entre 2 a 3 de estos (Espinoza Soriano 1967; Lerche 1992; Schjellerup 2005). Todos estos aspectos que la arqueología y etnohistoria necesitan aclarar y profundizar.

Al describir este territorio, el historiador Jorge Zevallos Quiñones (1987; 1995) menciona que algunos documentos de la administración virreinal indican 19 repartimientos registrados en los siglos XVII y XVIII, de los cuales Chachapoyas habría sido uno de ellos con su ubicación entre la Jalca Grande y Levanto en el tiempo de la colonia. Desde la organización del sistema de Hunos, la "provincia Inca de Chachapoyas" habría alcanzado un promedio de 30 mil tributarios según las versiones de los censos españoles, como refiere la Dra. Inge Schjellerup (2005: 72). 
La arqueología en la región, fundamentalmente en más del $90 \%$ de la parte central y sur del departamento, indica la existencia de una densa infraestructura cuyas características constructivas y arquitectónicas de sitios o asentamientos diversos muestran terrazas elevadas y monumentales; destacan construcciones de planta circular organizados de manera aglutinada o dispersos, asociados a espacios, sistemas de accesos y circulación, distribuidos en niveles aterrazados, todos de características residenciales; también resaltan construcciones de planta cuadrangular, rectangulares y mixtas con esquinas circulares.

La presencia de construcciones monumentales ubicadas en escenarios geográficos asociados a pasos naturales (tambos, miradores, caminos, etc.), son parte integrante del paisaje cultural ligado a la religiosidad y ceremonialidad ${ }^{1}$.

En lo que respecta a la tecnología constructiva básica y productiva en la región prehispáni$\mathrm{ca}$, mencionamos paisajes de andenes, sistemas de canales y algunas áreas de terrazas para el uso agrícola; también son evidentes la red de sistema de caminos que permitían el tránsito no solo a los poblados más importantes dentro de la administración Inca o local, sino con relación a

1 En varias conferencias y exposiciones el arqueólogo Alfredo Narváez Vargas ha venido promoviendo la interpretativa funcional de ceremonialidad al Templo Mayor refiriéndose a la construcción tronco cilíndrica ubicada en lo que fuera también denominado el sector de "pueblo bajo" (Narváez 1988; 1996) y que desde los años de sus primeros estudios a mediados del siglo XX fuera llamada también como "el tintero".

Aunque Alfredo Narváez no ha publicado el sustento de sus excavaciones y más aun de su análisis de resultados; sin embargo, debo decir que de nuestra parte hemos podido constatar que este tipo construcción monumental no es única en Kuelap, existen en el valle del alto Utcubamba más de cinco5 tipos de esta arquitectura (Molinete en Leymebamba, Congona en el Yeso, Muyupata en Jalca Grande, Churupunta en Levanto, Atunpucro en Lopecancha), ¿Es sólo una función ceremonial las que cumplieron estas construcciones en cada sitio? ¿Qué relación han tenido en el contexto del valle, más aun con respecto a la Fortaleza de Kuelap?, junto a estas interrogantes, nos desconcierta que no sean de ingeniería local aunque la mano de obra probablemente lo fuera, estoy seguro que más adelante podremos despejar este panorama incierto. la diversidad de recursos y zonas de extracción, esta infraestructura muestra el alto nivel de manejo espacial, topográfico de control político, administrativo e ideológico generando estrategias de servicios².

Todo este bagaje de evidencias han sido, en su gran mayoría, estudiados por distintos arqueólogos y especialistas (Reichlen 1950; I. Schjllerup 1976; Shady Solís 1972; Ruiz Estrada 1972; Church, Lenon y Cornejo 1979; Narváez 1987, 1999-2000, 2004, 2005, 2006, 2007, 20082010; Ruiz Barcellos 2002, 2003, 2004, 2005, 2006; Fabre y Ruiz Barcellos 2004; Kotchmieder 2009, 2010). Entre los datos recogidos por los arqueólogos, destaca el interés por la arquitectura y la cerámica, ésta última ha permitido que muchos propongan estilos de cerámica que han generado algunas asociaciones cronológicas ("Chipuric": Reichlen 1945; "Pumahuanchina, Kuelap e Inca": Ruiz Estrada 1970; "Cajamarca Cursivo, Kuelap aplicado": Narváez y Delgado 1999) incluso algunos han establecido tres momentos: Chachapoyas Temprano, Medio y Tardío (Schjellerup 2005), aunque en las últimas excavaciones del año 2010 efectuadas por Klaus Kotchmieder en el sitio Lamud urco en Luya, éste habría registrado fragmentos de cerámica formativa tardío e intermedio temprano (estilo Tosan), asumiendo, para este arqueólogo alemán, que no existe un Chachapoyas Temprano, Medio y Tardío, simplemente no hay Chachapoyas, siendo otros grupos de una vieja tradición (com. per. Klaus, Kotchmieder 2011).

2 Como ejemplo menciono la red del Qapac Nan, asociado a sitios tipo tambos como de Cochabamba a Puca urco cuya distancia es de $10,11 \mathrm{~km}$, también hemos observado lo mismo en el valle del Alto Utcubamba entre el sitio de Olan y la laguna de Mamacocha asociado a los sistemas de caminos que van a las fuentes de agua, quebradas, cordillera con extensiones de entre $10,14 \mathrm{~km}$ de distancia y en el caso de los lugares religiosos y ceremoniales que no necesariamente existe una infraestructura, así destacan los sitios de Olan, Ollape en Jalca Grande distan a la laguna de Mamacocha un promedio de 10,09 km o como el caso de la Fortaleza de Kuelap con respecto a Cuchacuella en una distancia de 10,10 km lineales. Pues lo que si nos admira es que en este décimo numérico kilometraje nos siga mostrando la planificación de Incas más que de locales, quizás deba ser esta también una problemática que debamos interesarnos en indagar. 
Las sociedades ancestrales en la región, también han expresando una serie de características que permiten dar a conocer sobre la tecnología mortuoria y momificación, además de los aspectos de mortandad, sean por enfermedades $\mathrm{u}$ otras causas provocadas, y sobre algunas patologías de algunos individuos. Todo ello necesita profundizarse (Horkheimer 1958; Kauffmann 2003; Schjellerup et. al. 1986-1987; Guillén 1999, 2003; Nystrom 2005; Morales, Valle y Church 2002; Toyle y Narváez 2007. 2008).

Sin embargo no hemos caracterizado el conocimiento poblacional de grupos étnicos desde sus rasgos antropofísicos y filogenia.

Sobre la región ancestral, no se ha estudiado sobre la religiosidad, aunque la información de los cronistas como Pedro Cieza de León y Albornoz indican que para la "nación Chachapoya", la huaca o dios más importante fue $\mathrm{Cu}$ chaycuella 3 (P. Duviols 1986).

Los estudios de las sociedades ancestrales han permitido también describirlos desde sus características vernaculares y dialectales, destacando los aportes etnolingüísticos pione-

3 Se trata de una laguna ubicada en las alturas cordilleranas del poblado de María, dista a 10,10 km lineales al oeste de la Fortaleza de Kuelap, sobre esta fuente de agua existe una serie de cuentos y leyendas (la laguna de Cuchacuella y el príncipe de Changali) en la que ésta representaría a la laguna hembra según la interpretación de la tradición oral. Alfredo Narváez reflexiona y menciona que esta laguna es la Pacarina de Kuelap descrita por los cronistas como el dios principal; sin embargo, nuestros estudios de campo han constatado en el tema de las lagunas como Pacarinas pues en la zona son diversas, en su mayoría de formación por filtraciones de agua de lluvia, y muy pocas de formación por desglaciación. Cuchacuella al parecer sería de origen por filtraciones.

La denominación de Pacarina, posee una explicación etnolingüística y simbólica propia, está relacionada al origen mítico de los pueblos y según refieren en su gran mayoría tanto los primeros historiógrafos como los estudiosos e investigadores, ésta estructura simbólica está distribuida por los Incas en todo el Tahuantinsuyo. Esto obliga a preguntarnos icuáles serían los dioses de las etnias locales?, si desde esta perspectiva y aun mas con los datos que muestran las evidencias, es muy probable que Cuchacuella o Cuchaycuella fuera la "Pacarina Inca de la Fortaleza de Kuelap". ros de Gerald Taylor (1975) y Alfredo Torero (1964). Estos investigadores han identificado una riqueza fonológica a través de la tradición oral; sin embargo, no existen estudios sobre aspectos estructurales del lenguaje simbólico, mucho menos relacionados a contextos de entendimiento ideológico y religiosidad; con todo ello se ha generado que se asuma a "los Chachapoyas" solo desde la perspectiva puramente historiográfica.

Con esta resumida caracterización que exponen los datos historicistas en la información sobre el departamento de Amazonas, las cuales refieren la existencia de un contexto cultural prehispánico denominado los Chachapoyas, asumimos que para caracterizarlo mejor debemos tomar el aporte de otras disciplinas.

Reflexionamos sobre la grafía Purum toda vez que los datos arqueológicos y de tradición oral son frecuentes y están inmersos en el mismo ámbito de lo referido a los Chachapoyas. Nosotros hemos creído por conveniente profundizar las reflexiones sobre los estudios etnolingüísticos y los elementos simbolizantes que posee estos, además de su relación con los datos de la narrativa tradicional, todo ello desde un análisis estructural; siendo así analizamos las grafías Chacha, Puya y Purum, presentes desde el contexto ancestral de la región.

Sobre lo mencionado nos permitimos preguntarnos: ¿Cuál es la importancia de los términos y/o grafías Chachapuya y Purum en el entendimiento de las sociedades tardías en Amazonas? ¿Es posible que estos términos y/o grafías indiquen categorías de identidad y simbolización en la estructura de las sociedades tardías?, creemos que a continuación podremos ir reflexionado sobre estas preguntas e identificando algunas respuestas.

\section{Chachapoya y Purum. \\ ANTECEDENTES Y FUENTES}

\section{De lo Chachapoya}

A cerca de la palabra castellano conformada por dos grafías Chacha y poya o puya, una primera información nos la brinda el Cronista Inca 
Garcilaso de la Vega tomada a través del padre Blas Valera, quienes lo traducían como "lugar de varones fuertes", sin embargo "Actualmente, la forma Quechua de esta palabra es /sacapuyu/ castellanizada como Sachapuyu o Chachapuyu" (Taylor 2000). Otros estudiosos han referido que la grafía tiene un origen Aymara (Weiss 1949; Middendorf [1882] 1970); su explicación final por parte de algunos arqueólogos es que la palabra Chachapoya, significaba "hombre, gente o pueblo de las nubes” (Kauffmann 2003).

Sobre la lingüística en la zona debemos mencionar que cerca a la primera mitad del siglo XX, A. Bandelier (1929) al visitar la región menciona que la mayoría de los indios eran quechua hablantes. "Hoy solo algunos ancianos lo hablan a manera de monolingüismo durante ocasiones especiales como ceremonias o celebraciones tradicionales" (Taylor 2000: 42).

Los estudios iniciales sobre el quechua en los Chachapoyas apenas describe algunos morfemas, así, por ejemplo, en la bibliografía de Rivet y Créqui- Montfort dicen que el quechua de Maynas podría ser más antiguo que el ecuatoriano o quizás un antepasado de las hablas actuales de Chachapoyas y Lamas.

Por otro lado, en 1929 F. M. Pizarro publica el Ashlla Runa-Simi-Pa, el cual describe palabras siguiendo la gramática del quechua sureño; asi mismo en el año 1974 el Instituto Lingüístico de Verano difundió Apuntes sobre el quechua de Lamud de David J. Weber presentando el registro de microfichas; luego Carmelo Chaparro en 1985 publicaría Fonología y lexicón del quechua de Chachapoyas, describiendo las hablas de alto Imaza.

Sobre el estudio científico de la dialectología y lingüística son escasos, siempre se ha visto desde la perspectiva puramente vernacular, más no de la comprensión que ésta forma parte de una unidad de lenguaje y de comunicación cuya semiología estamos empecinados en identificar y comprender.

\section{De lo Purum}

Uno de los primeros historiógrafos en describir sobre la grafía "purun", "purum", o "porun" y "po- ron" es Guaman Poma de Ayala (1993 [1616]: Vol. 3, 108) indicando que se traduce como "bárbaro, salvaje, sin cultivar; natural". Este es usado para referirse de manera metafórica en su descripción sobre las "edades del mundo andino" en el cual la edad catalogada como "Purun runa" es un contexto de simbolización que es necesario profundizar su estudio.

También el jesuita Gonzales Holguín (1952 [1608]: 297), recopila una serie de vocablos constituidos con la grafía "purum"; así por ejemplo "purum runa poques" lo define como "bárbaro salvaje".

Por otro lado, la historiadora Sandra Sánchez menciona que Levillier (1920 [15831600]: tomo II: 225) describe "purummarca" referiéndose a indios que habitan el pueblo, el valle y quebrada del mismo nombre en la zona de Omaguaca, cuyo atributo era "ser indios de guerra belicosos". También es mencionado por la historiadora Sánchez que el significado de "purummarca" es puerta, camino y acceso a los despoblados de la puna y susques a la manera de un límite suroeste, así lo describe la antropóloga chilena Viviana Manríquez (2002: 341).

Con todo ello, debemos destacar los aportes de otros tratadistas que refieren y brindan información sobre "purum", El padre Ludovico Bertonio (1984 [1612]: tomo II) menciona que la grafía "purum haque" es Aymara y significa "hombre por no sujetar, sin dios, ni ley". Bernabé Cobo ( 1964 [1653]: vol.161) menciona que "pururáucas" -como lo escribe él mismohabría sido una fábula o invención del Inca Viracocha para nombrar a la "gente de socorro" y que supuestamente fueron enviados por el dios Viracocha; en síntesis, su denotación está referida a "ladrones escondidos" o "traidores escondidos".

Finalmente diremos que para poder analizar con más profundidad sobre estos aportes que básicamente son historiógrafos de la época colonial, es necesario saber y conocer sus variables etnolingüísticas con la finalidad de entender su significado, de esta manera podremos ubicar nuestro análisis de correspondencia o no, en el conocimiento de la identidad de 
las sociedades ancestrales en el departamento de Amazonas, perspectivas que la arqueología deberá redefinir, relacionando a la información etnohistórica.

\section{DESCRIPCIÓN E INTERPRETATIVA ETNOLINGÜÍ́sTICA QueCHUA Y AyMARA De los términos Chacha/Puya y PURUM}

Hemos efectuado una revisión de algunas fuentes lingüísticas y diccionarios que nos indiquen la mayor cantidad de interpretaciones acerca de estos términos.

En primer lugar nuestra búsqueda ha llevado a comprender que ambos poseen una morfología lingüística de dos orígenes, por un lado el quechua con sus significancias y tipos, por otro lado el aymara; en ese sentido decimos que estos dos orígenes lingüísticos de alguna manera nos indican que por lo menos los términos Chachal puya como Purum no son de formación local en el actual departamento de Amazonas.

\section{Sobre las grafías Chacha/puya}

Hemos podido observar que en los diccionarios quechuas no existe el vocablo "Chacha", mientras que la grafía "Puy" se traduce como "nube". Sin embargo "Chacha" si está presente en el lexicón Aymara. Tampoco, Chachapoya existe como una sola palabra o grafía, por lo que se deduce que es la unión de "Chacha" en aymara, que significa, en términos generales, "hombre", y "Puya", también aymara, actualmente utilizado, significa "mazorca de maíz seco".

Revisemos un poco más sobre el significado de "Chacha". Según refiere el diccionario bilingüe Iskay simipiyuyayk'ancha cuyo autor es el Dr. Teófilo Layme Ajacopa, editado en su segunda edición en La Paz, Bolivia del año 2007, hace referencia de diversos significados relacionados a este término, a decir:

- Chacha: esposo

- Chacha: Hombre

- Chacha: Hombre, varón

- Chacha: Valiente

- Chacha: Varón- simplemente
- Chacha-uaina: marido

- Chachasiña: casarse

- Chachani: mujer casada

- Chachapuro: entre hombres

- Chachakuma: planta medicinal

Es de observar que los significados o acepciones son diversas. Si organizamos cada una de ellas, podremos encontrar algunos grupos; tal es así que existen los grupos de Chacha, referidos a hombre biológicamente hablando, hombre en el sentido de agrupación de personas, hombreesposo referido a estatus familiar cuya unidad es una norma ancestral y que hoy los pueblos del centro, sur peruano y en Bolivia siguen festejando atraves del ritual del Chacha-warmi.

En lo que respecta a "Puya", éste posee una significancia desde el aymara, su traducción es "mazorca de maíz seco" relacionado a algunas actividades productivas como por ejemplo el que efectúan todavía las comunidades del alto Utcubamba ligado al preparado al harina de maíz; en todo caso la palabra actual de Chachapoyas, posee una morfología desde la época de la Colonia, la cual no ha cambiado. La grafía "Puya" es la que analizaremos con más detenimiento considerando ésta la aplicación original y no la grafía "puy" habiendo sido objeto de diversas interpretaciones por estudiosos e incluso a la fecha utilizada solo desde una descripción historicista por parte de los educadores en la zona.

\section{Sobre la grafía "Purum"}

Para el caso de la grafía "Purum", debemos mencionar que su traducción lo encontramos tanto en la lengua quechua como en el Aymara, existiendo mas traducciones y significancias en quechua; en algunos casos es escrito en el castellano de época colonial como "Purun" o sus variantes "porun" y "poron". Solo que en el caso de la escritura en morfema aymara se agrega la "a" y cuya morfología sería "Puruma" en ambos posee una traducción genérica referida a terrenos con cultivo, en quechua o "Puruma", terreno sin cultivo en aymara; finalmente se trata de terrenos-espacios. 
Con todo ello es importante dar a notar las distintas traducciones que le dan diversos estudios y que en todo caso son producto de los recojos de información etnográfica o en algunos casos procedentes de diccionarios (Cuadro 1).

En el Cuadro 1 observamos significancias y acepciones, indistintamente a sus orígenes lingüísticos; describe lo biológico, mencionan distinciones "salvajes", "bárbaros"; distinciones de lugar: "montañas" y "tierras vírgenes"; "despoblados", "apartados - separados de la "civilidad", "terrenos yermos", "sin cultivar", "montañosos"; pero también referido a "traidor", "enemigo; en conclusiones, la polisemia de Purum comunica cualidades y atributos; permitiendo distinciones y por consiguiente clasificando una denotación de identidades.

Si bien es cierto en el departamento de Amazonas existe un estudio dialectal que requiere profundizar y actualizar ampliamente; sin embargo no se ha efectuado un análisis detallado sobre formas y figuras estructurales relacionadas al lenguaje, nosotros queremos destacar que en el caso de las grafías Puya y Purum conectados a las acepciones de "Chachapoyas", éstas se encuentran relacionadas a una serie de características y elementos antropológicos, simbólicos y arqueológicos.

\section{ElEMENTOS ARQUEOLÓGICOS RELACIONADOS al contexto de Puya y Purum}

La palabra Purun o Purum, en el departamento de Amazonas, definitivamente no solo está relacionado a espacios y contextos de antiguos usos, sino que denotan distinciones mantenidas por los actuales pobladores, refiriéndose a la antigua gente que habitaba anteriores poblaciones, y que hoy solo quedan algunos vestigios.

Los tipos de evidencias arqueológicas a las cuales los pobladores de las comunidades se refieren básicamente son de tipo residencial o habitacional y de tipo funerario; así por ejemplo debemos mencionar algunos de ellos, el primero es Purum Llacta en San Juan de Chetoprovincia de Chachapoyas; ubicado a $2580 \mathrm{~m}$. s. n. m. con un área aproximada de 120 has., la presencia de 12 sectores arqueológicos y en el que se distinguen construcciones de planta circular sean estas residenciales aglutinadas o dispersas, asociadas por sistemas de accesos con plataformas o basamentos residenciales; también son frecuentes las estructuras de planta cuadrangular y rectangular, además la presencia en sistemas de accesos que permiten distinguir una organización del asentamiento de diferente forma. Nuestros estudios del año 2002 y 2003 permitieron asumir que en Purum Llacta se dedicaron en algún momento de su establecimiento de manera especializada a la agricultura debido a la innumerable presencia de instrumentos de labranza que ubicamos en algunas de las construcciones (Barcellos 2004).

El sitio arqueológico de Purum Llacta en el actual distrito de San Miguel de Soloco, es un asentamiento ubicado a mas de 2850 m. s. n. m., sus características constructivas nos muestran una arquitectura residencial de planta circular sobre basamentos y estos distribuidos a modo de unidades sobre importantes muros perimetrales con más de $12 \mathrm{~m}$ de alto $^{4}$, sus construcciones habitacionales poseen una marcada factura de tipo cilíndrico y cónico en la parte superior de sus muros. Su nombre es otorgado por los pobladores, refiriéndose a su distanciamiento y despoblado.

Entre el distrito de Magdalena y Levanto se ubica el sitio arqueológico de Purum Llacta, a una altura de 2860 m.s.n.m. expone características residenciales combinando entre formas arquitectónicas prehispánicas, Incas e hispánicas; existen una serie de leyendas sobre este sitio en el que se explican su desocupación, abandono y movilidad de gentes de este lugar.

4 El año 2004 en el proyecto de prospecciones de la minicuenca del Olia (Fabre y Barcellos 2004) pudimos efectuar algunos sondeos en este sitio y medimos las dimensiones de algunas terrazas. Considero que entre el valle alto del Utcubamba y Sonche, Purum Llacta de Soloco es el sitio que mayormente muestra una volumetría elevada, exponiendo una visual monumental, lo cual podría ser el sitio arqueológico tipo conjuntamente con el sitio de la "Fortaleza de Kuelap"cuyas terrazas o plataformas adoptan medidas entre 15 a más metros de alto. 
Cuadro 1: Traducciones dadas acerca de la grafía Purun o Purum

\begin{tabular}{|c|c|c|c|}
\hline Términos & $\begin{array}{c}\text { Origen } \\
\text { Etnolingüístico }\end{array}$ & Traducción & Fuentes: \\
\hline $\begin{array}{l}\text { Purun } / m \text {, [variantes } \\
\text { porun o poron] }\end{array}$ & Quechua & $\begin{array}{l}\text { "bárbaro, salvaje, sin cultivar, } \\
\text { natural" }\end{array}$ & $\begin{array}{l}\text { Guamán Poma de Ayala } 1993 \\
\text { [1616]:vol.3,pág.108 }\end{array}$ \\
\hline Purun runa & Quechua & "Hombre /gente bárbara" & $\begin{array}{l}\text { Guamán Poma de Ayala } 1993 \\
\text { [1616]:vol.3,pág.52 }\end{array}$ \\
\hline Purum & Quechua & $\begin{array}{l}\text { "hombres, salvajes, no } \\
\text { conquistados, desierto o } \\
\text { despoblado }\end{array}$ & $\begin{array}{l}\text { Jesuita Gonzales Holguín } 1952 \\
\text { [1608]:297 }\end{array}$ \\
\hline Purum runa poques & Quechua & $\begin{array}{l}\text { "bárbaro, salvaje, gente que } \\
\text { no tiene ni ley ni rey; desiertos } \\
\text { y despoblados" }\end{array}$ & $\begin{array}{l}\text { Jesuita Gonzales Holguín } 1952 \\
\text { [1608]:297 }\end{array}$ \\
\hline Purumamarca & Quechua & $\begin{array}{l}\text { "indios que habitaron pueblo, } \\
\text { valle y quebrada ; tierra de } \\
\text { indios de guerra belicosos" }\end{array}$ & $\begin{array}{l}\text { Levillier } 1920 \text { [1583-1600]: } \\
\text { tomo II,225. }\end{array}$ \\
\hline Purumamarca & Quechua & $\begin{array}{l}\text { "la puerta, el camino y los } \\
\text { accesos a los despoblados de la } \\
\text { Puna y Susques a la manera de } \\
\text { un límite suroeste" }\end{array}$ & Sánchez Sandra ,1996 \\
\hline Purun qullqui & Quechua & "plata bárbara o natural" & Jan Szeminski \\
\hline Purun quri & Quechua & "oro salvaje o en pepitas & Jan Szeminski \\
\hline Purun warmi & Quechua & "mujer bárbara" & Jan Szeminski \\
\hline $\begin{array}{l}\text { Purunauca o } \\
\text { Purumauca }\end{array}$ & Quechua & $\begin{array}{l}\text { "enemigo, traidor, contrario, } \\
\text { adversario }\end{array}$ & $\begin{array}{l}\text {-Guamán Poma de Ayala } 1993 \\
\text { [1616]:vol.3, pág.28. } \\
\text {-Jesuita Gonzales Holguín } 1952 \\
\text { [1608]: } 38 . \\
\text {-Lenz 1992 [1909-1910]:55 }\end{array}$ \\
\hline Puruma & Aymara & $\begin{array}{l}\text { "terreno sin cultivar, virgen, } \\
\text { despoblado, sitio o casa } \\
\text { apartada" }\end{array}$ & $\begin{array}{l}\text {-Diccionario de Quechua y } \\
\text { Aymara de www. katari.org. }\end{array}$ \\
\hline Puruma haque & Aymara & $\begin{array}{l}\text { "los hombres por sujetar sin } \\
\text { dios ni ley }\end{array}$ & $\begin{array}{l}\text { Ludovico Bertonio } 1984 \\
\text { [1612]:tomo II. }\end{array}$ \\
\hline Pururáucas & Aymara & $\begin{array}{l}\text { "ladrones escondidos, } \\
\text { traidores escondidos" }\end{array}$ & $\begin{array}{l}\text { Bernabé Cobo } 1964 \\
\text { [1653]:vol.161 }\end{array}$ \\
\hline Purum sallqa k'ita & Quechua & "anda por los montes & $\begin{array}{l}\text { Diccionario Bilingüe Iskay } \\
\text { simipiyuyayk'ancha } 2007\end{array}$ \\
\hline Purum si & Quechua & "terreno yermo, desabrigado" & $\begin{array}{l}\text { Diccionario Bilingüe Iskay } \\
\text { simipiyuyayk'ancha } 2007\end{array}$ \\
\hline $\begin{array}{l}\text { Purumtasqa, llum'aq, } \\
\text { llump'a }\end{array}$ & Quechua & $\begin{array}{l}\text { "Inmaculado que no tiene } \\
\text { mancha" }\end{array}$ & $\begin{array}{l}\text { Diccionario Bilingüe Iskay } \\
\text { simipiyuyayk'ancha } 2007\end{array}$ \\
\hline Purum & Quechua & $\begin{array}{l}\text { "campesino, cosa del campo, } \\
\text { categoría social baja" }\end{array}$ & $\begin{array}{l}\text { Fray Domingo de Santo Tomas } \\
1951 \text { [1560], en Rostworowski } \\
\text { María, 1993 }\end{array}$ \\
\hline
\end{tabular}


Con respecto a los espacios ancestrales funerarios que nos llaman la atención por su ubicación, ubicuidad y su policromía decorativa que une la vida con la muerte destacando los mausoleos de Revash, Atunpucro, Tin Tin, y del tipo "sarcófago" como en Karajía, Solmal, Inguilpata, puente Utcubamba, Caclic, etc. en el Valle del Utcubamba.

En el caso de los denominados "sarcófagos", que son efigies antropomorfas ubicadas en peñas y en algunos casos en cuevas, son repositorios de entierros ya sean humanos y de animales; a estos repositorios la población en el lenguaje tradicional los denominan Purunmacho ${ }^{5}$.

En el caso de la grafía Puyan o "Puy" o "Puyo", como se relaciona a varios sitios arqueológicos, debemos mencionar por ejemplo el sitio de Puyan, ubicado en el distrito de Levanto a 2814 m.s.n.m., cuyas características constructivas son peculiares.

Se trata de un asentamiento que se distribuye en dos conceptos: construcciones aglomeradas y construcciones con el modelo disperso sobre una cima.

Actualmente el sector de construcciones aglomeradas se encuentra cubierto por densa vegetación, sin embargo por información del arqueólogo Manuel Malaver Pizarro funcionario de la Dirección Regional de Cultura de Chachapoyas - Amazonas estas construcciones son circulares de tamaños homogéneos distribuidas sobre sistema de plataformas, él asume que se trataría de posibles depósitos o almacenes. En este sitio no se han efectuado excavaciones arqueológicas para asegurar esta hipótesis; sin embrago la traducción de la grafía indica una relación con su origen etnolingüístico.

En el valle del alto Utcubamba existe un sitio arqueológico, su denominación es "Intipu-

5 La grafía Purum en quechua o aymara, hemos descrito que está fundamentalmente relacionado a despoblado, lugar abandonado por gente no civilizada o "bárbara", como lo refieren las fuentes que hemos expuesto en líneas arriba, sin embargo la grafía Machu en quechua se traduce como "viejo"- referido a personas viejas, en el contexto de la significancia de "Purummachu" podríamos indicar que se refiere a "lugar despoblado con gente vieja o antigua no civilizada". yo" о "Ingaриуо"6, su altura sobre el nivel del mar es de $3068 \mathrm{~m}$ aunque el sitio está bastante agredido por las acciones agrícolas, sin embargo se puede distinguir algunas de sus construcciones podrían ser sistemas de plataformas circulares, además hay evidencias en cabeceras de muros de estructuras habitacionales y muchos espacios amplios a manera de plazas. El Dr. Arturo Ruiz Estrada en sus visitas que efectuó el año 1969, menciona que este sitio está compuesto por tres plataformas y que "Por la ladera Norte de Ingapuyo existen varios recintos circulares destruidos, en los cuales se observa que fueron levantados con un aparejo tipo pachilla." (Ruiz Estrada 2010: 68)

En relación a todos estos sitios arqueológicos existen elementos míticos transmitidos a través de la tradición oral, elementos que complementan la estructura simbólica que también contextualiza de manera específica a la grafía Purum más que a las grafías Chacha o Puya que al parecer poseen otra connotación de identidad.

\section{ELEMENTOS ETNOGRÁFICOS DE}

\section{LA TRADICIÓN ORAL RELACIONADOS al contexto simbólico de PuRum}

Para poder enmarcar este contexto desde el aporte de las referencias etnográficas transmitidas a través de la tradición oral, sean estos de cuentos y/o leyendas ${ }^{7}$, debo mencionar en pri-

6 Muchos de los lugareños me han comentado que el sitio se denomina "Intipuyo"; al respecto debo indicar lo siguiente: la grafía compuesta de Inti/puyo o Inti/ puya, lo podemos enunciar de la siguiente manera, Inti es una grafía de origen morfológico quechua, está referida al "Sol" como uno de los dioses tutelares creados en el tiempo de la mascaypacha de Viracocha (siglo X-XI) y expandidos conjuntamente con la conquista Inca en el Tahuantinsuyo. La grafía Puya que hemos explicado en líneas arriba- es aymara, se traduce como "mazorca de maíz seco".

7 Particularmente considero que las fuentes orales no son aisladas, conforman parte de una estructura de comunicación y lenguaje cuyos orígenes poseen relaciones secuenciales homogéneas o heterogéneas, fundamentalmente no podemos tratar de interpretar con una metodología de estructura, morfemas, ritmos, sonidos y simbolizaciones a través de cuentos y leyendas desde la narrativa occidental, sin embargo, están mezcladas con la estructura de factura propia con particularidades locales andino-amazónicas. 
mer orden existe un 90\% de las mismas relacionadas a dos aspectos: alteraciones climáticas y a las identidades; éstas se mesclan con el simbolismo que están transmitiendo de aquello que está denominado como lo Purum.

Existen narraciones diversas en la mayoría de provincias y distritos fundamentalmente concentrados entre Chachapoyas, Luya, Bogará y Rodríguez de Mendoza en los cuales se denota estas características ${ }^{8}$, de manera que una peculiaridad es que en casi todas las narraciones los elementos que la conforman denotan una estructura integral de la comunicación simbólica.

Para poder especificar las características de estas tradicionales orales, debemos mencionar que Purum posee diversos atributos que son identificados por los historiógrafos coloniales, como por algunos investigadores; asi lo han notado G. Poma 1993 [1616]; G. Holguín 1952 [1608]; L. Bertonio 1984 [1612]; B. Cobo 1964 [1653]; L. Huertas 1990; S. Sánchez 1996; E. Cáceres 2002; V. Manríquez 2002, en ese sentido ubicaremos las narraciones que venimos registrando y estudiando desde dos grupos de antecedentes de los historiógrafos del siglo XVI o de algunos investigadores más actuales.

Para ello adoptamos las siguientes variables que permitirán presentar mejor las narraciones y tradiciones que venimos registrando y con las cuales expondremos nuestras analogías estructurales.

8 Hemos iniciado el año 2010 un registro de narraciones orales y tradiciones; hasta la fecha hemos venido documentado un promedio de 125 narraciones fundamentalmente procedentes de las provincias de Chachapoyas, Luya, Bongará y Rodríguez de Mendoza; sin tener todavía información de la parte norte del departamento como son Bagua, Utcubamba y Condorcanqui.

Nuestro trabajo ha implicado identificar varios aspectos que destacan elementos simbólicos ligados a la ideología andina evidente en todos ellos, esto nos permitirá poder observar que por lo menos desde estos niveles se pueden identificar elementos de identidad marcados en la zona y por consiguiente desde estas perspectivas generar algunas respuestas sobre aspectos como los Chachapoya(s), los Incas y otros grupos ubicados en el contexto de las denominadas sociedades tardías en la región. $1^{\circ}$. Varios atributos-significancias desde la descripción del Cronista Guamán Poma de Ayala en su obra de 1616 cuando describe "la tercera edad del mundo andino":

Los atributos que describe Guaman Poma de Ayala, permite mesclar figuras hispanas con andinas, utilizando en algunos casos frases metafóricas, refiriéndose a la edad de "Purun runa" o "tercera edad" en el Mundo Andino, las frases y descripciones mencionadas son :

$\checkmark$ Descripciones de las alteración climática o "diluviales"

$\checkmark$ Se describen el origen de la población y/o comunidad.

$\checkmark$ Se distinguen a los Incas de otros grupos.

$\checkmark$ Se enuncia el papel de la guerra y los conflictos.

$\checkmark$ Se describe la abundancia.

$\checkmark$ Se describen la construcción de casas edificadas con piedra y techos de paja.

$\checkmark$ Se enaltecen las reuniones públicas en plazas, con música y danzas.

$\checkmark$ Se describe la ganadería, agricultura y pastoreo sobre salientes.

$\checkmark$ Se destaca el impulso por la construcción de caminos.

$\checkmark$ Destacan la importancia del papel de "Rey", "señores" y capitanes fundadores.

$\checkmark$ Se menciona y relaciona a Uari Uiracochacomo "dios" que continua desde la primera edad.

Todas estas características establecen y describen cualidades étnicas de o los grupos, en este contexto existen distintas narraciones en las provincias fundamentalmente de Chachapoyas, Luya, Bongará y Rodríguez de Mendoza que denotan cualidades y atributos para recrear la argumentación de distinción que describen grupos locales y foráneos siendo los Incas y consecuentemente los Españoles de mayor implicancia en estas distinciones (Cuadro 2).

Debemos indicar que las narraciones expuestas son una muestra de la cantidad de los relatos relacionados a los contextos de significancia vinculantes a la estructura que describe el cronista Guaman Poma de Ayala cuando se refiere al tiempo de los "Purun runa", podríamos 
Cuadro 2: Relatos y Narraciones relacionadas al concepto de Purun runas de Guaman poma de Ayala 1616

\begin{tabular}{|c|c|c|c|}
\hline Narración y/o relato & Lugar y fuentes & $\begin{array}{c}\text { Atributo } \\
\text { relacionado }\end{array}$ & Breve descripción del relato \\
\hline $\begin{array}{l}\text { Leyenda de la "Laguna } \\
\text { de Pomacochas" }\end{array}$ & $\begin{array}{l}\text { Bongará/ Gerald } \\
\text { Taylor } 1996\end{array}$ & $\begin{array}{l}\text { "diluvial" } \\
\text { alteraciones } \\
\text { climáticas/laguna } \\
\text { hembra. }\end{array}$ & $\begin{array}{l}\text { "Laguna que se molesta y hierve, luego hace } \\
\text { llover intensamente, antes un anciano avisa } \\
\text { a un hombre y su hermana para que se suban } \\
\text { al cerro más alto y se protejan" }\end{array}$ \\
\hline $\begin{array}{l}\text { Leyenda de la "Laguna } \\
\text { de Vilaya" }\end{array}$ & $\begin{array}{l}\text { Colcamar-Luya/ } \\
\text { Gerald Taylor } \\
1996\end{array}$ & $\begin{array}{l}\text { "diluvial" } \\
\text { alteraciones } \\
\text { climáticas/laguna } \\
\text { hembra. }\end{array}$ & $\begin{array}{l}\text { "Laguna brava que una bruja busca a un } \\
\text { hombre para ir a calmarla y le ofrecen varia } \\
\text { cosas, sino tiraban tres pedernales, la laguna } \\
\text { se comía todo lo encontraba en el pueblo" }\end{array}$ \\
\hline $\begin{array}{l}\text { Leyenda de la "Laguna } \\
\text { de Mamacocha" }\end{array}$ & $\begin{array}{l}\text { Jalca Grande/ } \\
\text { Boletín "Kuelap" } \\
\text { del INC, N¹05, } \\
1994\end{array}$ & $\begin{array}{l}\text { "diluvial" } \\
\text { alteraciones } \\
\text { climáticas/laguna } \\
\text { hembra }\end{array}$ & $\begin{array}{l}\text { "Una niña es tragada por la laguna y un } \\
\text { padre intenta salvarla, pero se queda } \\
\text { encantada y le entrega dos tesoros al } \\
\text { padre, uno le da animales, el otro tesoro } \\
\text { es una cántaro con agua, ya nadie pasaba } \\
\text { necesidades en el pueblo." }\end{array}$ \\
\hline $\begin{array}{l}\text { Leyenda del "Origen de } \\
\text { la comunidad antigua } \\
\text { de la Jalca" }\end{array}$ & $\begin{array}{l}\text { Jalca Grande/ } \\
\text { Gerald Taylor } \\
2003\end{array}$ & $\begin{array}{l}\text { "población o } \\
\text { comunidad", } \\
\text { disputas, } \\
\text { identidades, héroes } \\
\text { re-fundadores" }\end{array}$ & $\begin{array}{l}\text { "El obispo Santo Toribio llegó a la Jalca } \\
\text { cuando los kulungos se estaban peleando } \\
\text { entre sí, él lo separó y ordenó que adorasen } \\
\text { a un bastón de plata, luego formó los cuatro } \\
\text { barrios tradicionales; asíllegó la calma al } \\
\text { pueblo" }\end{array}$ \\
\hline $\begin{array}{l}\text { Leyenda: "La fiesta del } \\
\text { techado de casas en la } \\
\text { Jalca Grande" }\end{array}$ & $\begin{array}{l}\text { Jalca Grande/ } \\
\text { Informante: } \\
\text { Alonsio Huamán } \\
\text { Huamán }\end{array}$ & $\begin{array}{l}\text { "Construcción de } \\
\text { casas" }\end{array}$ & $\begin{array}{l}\text { "La gente organiza el techado de su casa } \\
\text { luego de la fiesta de la construcción y este } \\
\text { techado es con música y danzantes" }\end{array}$ \\
\hline $\begin{array}{l}\text { Leyenda de "Plazapiche } \\
\text { y el cura de Purum } \\
\text { Llacta" }\end{array}$ & $\begin{array}{l}\text { San Cristóbal } \\
\text { de Cheto- } \\
\text { Chachapoyas. }\end{array}$ & $\begin{array}{l}\text { "Fiesta de la plaza } \\
\text { en junio" }\end{array}$ & $\begin{array}{l}\text { "el pueblo de Cheto en el mes de junio lleva } \\
\text { al cura del pueblo al antiguo poblado de } \\
\text { Purum Llacta y lleva a cabo la misa, pero } \\
\text { además realizan una fiesta en las plazas de } \\
\text { Purum llacta, donde comen, beben, danzan y } \\
\text { hay músicos". }\end{array}$ \\
\hline $\begin{array}{l}\text { Leyenda de la "Fiesta de } \\
\text { Kulungus" }\end{array}$ & $\begin{array}{l}\text { Jalca Grande/ } \\
\text { Gerald Taylor } \\
1996\end{array}$ & $\begin{array}{l}\text { "Fiesta de } \\
\text { Kulungus" }\end{array}$ & $\begin{array}{l}\text { "Los Kulungus son las antiguas gentes de } \\
\text { Ollape que siempre están haciendo fiestas, } \\
\text { cuando los campesinos caminan por ahí con } \\
\text { sus animales estos desaparecen, pero luego } \\
\text { de } 7 \text { días aparecen nuevamente" }\end{array}$ \\
\hline $\begin{array}{l}\text { Leyenda "La quena de } \\
\text { Huacapampa" }\end{array}$ & $\begin{array}{l}\text { Cheto- } \\
\text { Chachapoyas/ } \\
\text { Boletín del INC } \\
\mathrm{N}^{\circ} 105,1994\end{array}$ & $\begin{array}{l}\text { "músico, } \\
\text { identidades" }\end{array}$ & $\begin{array}{l}\text { "Un indio que llegó de muy lejos se enamoró } \\
\text { de la princesa de Huacapampa, ella le dijo } \\
\text { que no tenían comida y agua en su pueblo y } \\
\text { el trajo la comida y el agua, después de eso la } \\
\text { princesa se fue, desde ese entonces sentado } \\
\text { en una piedra alta este indio toca su antara } \\
\text { muy triste" }\end{array}$ \\
\hline $\begin{array}{l}\text { Leyenda de "La hija } \\
\text { del cacique Loloc de } \\
\text { Levanto y general Inca" }\end{array}$ & $\begin{array}{l}\text { Levanto- } \\
\text { Chachapoyas/ }\end{array}$ & $\begin{array}{l}\text { "pareja e } \\
\text { identidades" }\end{array}$ & $\begin{array}{l}\text { "Un general que llegó de muy lejos se } \\
\text { enamoró de la hija del cacique Loc loc en } \\
\text { Levanto, esta le dijo que le aceptaba si } \\
\text { construía un canal de agua para su pueblo, el } \\
\text { general lo construyó y luego la hija no quiso } \\
\text { casarse entonces Loc loc expulsó al general } \\
\text { y sus soldados de Levanto, lo que hizo el } \\
\text { enojo de este y mando destruir el canal de } \\
\text { Ayshpachaca. }\end{array}$ \\
\hline
\end{tabular}


adelantarnos y decir que en este caso se entre mesclan estos elementos de manera simbólica referidos a los atributos de este tiempo, aunque en la mayoría de los relatos destacan cualidades de identidades que uno de estas denominaciones se simboliza en la grafía de Kulungus ${ }^{9}$.

Aunque por el momento, desconocemos con exactitud si es que la denominación Kulungus, es de origen prehispánico local; pero si podemos decir que los actuales poblados de Jalca Grande, Santo Tomás de Quillay, San Pedro de Uta, etc. Utilizan esta distinción, no siendo asi en los poblados de Magdalena, el tingo, en la parte interior del Utcubamba.

De todos estos elementos y atributos identificados en las narraciones y relatos, es uno el que destaca permanentemente, referido precisamente al atributo de alteraciones climáticas o en este caso el ocaso o transformación, expresado a través del significado del "diluvio".

$2^{\circ}$. Significancias desde el elemento diluvial- alteraciones climáticas relacionadas a Purum tomado los aportes del Cronista G. Ayala, de algunos investigadores y del trabajo de Efraín Cáceres referido al registro en la tradición oral de la comunidad de Acomayo en el departamento del Cusco

Debemos aclarar que el atributo diluvial, tiene varias significancias relacionadas a:

Alteraciones climáticas registradas del siglo XI de nuestro tiempo

$\checkmark$ Significancia de transformación de nuevos tiempos.

$\checkmark$ Relacionado a lo no civilizado por lo civilizado (simbolización Inca/ Hispana)

Estos atributos que hemos identificado tanto en las descripciones de Guamán Poma de Ayala,

9 Es una categoría de mucha relación con los Purum, pero al parecer es única en determinadas zonas de la región, aun no he podido identificar esta grafía en otros contextos quechuas o aymaras, aunque podría existir algunas similitudes en aymara con la grafía K'ullujinchu que quiere decir persona caprichosa o desobedientes; de alguna manera se relaciona, ya que en los poblados de Santo Tomás de Quillay o Jalca Grande, una de sus características están referidas a esas descripciones. como en otros historiógrafos de la época Colonial, asi como el aporte valioso del Antropólogo Efraín Cáceres estarían relacionados a algunos documentos de tradición oral, que hemos venido registrando (Cuadro 2). En todos los casos "la simbolización de la dinámica" ha estado caracterizado por el atributo de movilidad que los grupos han expresado, donde los contextos geográficos han sobresalido, habiendo sido esta característica que los ancestrales poblados a tenido debido a cambio de escenarios ecológicos.

\section{El SIMBOLISMO DEL AGUA Y SU RELACIÓN CON la significancia de Purum}

En otro artículo sobre simbolización desde el estudio de figuras, iconografía y arte rupestre asociado a contextos funerarios, hemos argumentado que uno de los más importantes eventos míticos en la región esta caracterizado por la comunicación y lenguaje del "agua" a través de la estructura simbólica que hemos categorizado como circunforme de la "vida y de la muerte" (R. Barcellos 2011a), e inicio y final de un proceso socio cultural como lo ha referido el Dr. Efraín Cáceres (2002).

Esta estructura simbólica circunforme y dialéctica en el pensamiento generacional de los grupos humanos, en el caso de las sociedades tardías; habrían tenido un contexto sociocultural de normas y leyes que rigieron en los niveles organizacionales, políticos y religiosos para un mayor manejo y control de masas.

Desde esta premisa, deseo explicar que en el contexto de la significancia agua y su relación Purum, podemos decir que posee su propia dinámica y por consiguiente sus elementos singulares que los identificamos y organizamos con su estructura y que en un futuro cercano podremos decir más desde la explicación iconológica de los mismos.

\section{Identidades de los elementos iconológicos}

Los elementos que hemos identificado en los relatos y narraciones están conformados por "el agua”, caracterizada por las lagunas, lluvias y tempestades; "la tierra" por los cerros y cordi- 
Cuadro 3: Relatos y Narraciones relacionados a elementos diluviales que posee Purum

\begin{tabular}{|c|c|c|c|}
\hline $\begin{array}{l}\text { Narración y/o } \\
\text { tradición oral }\end{array}$ & Lugar/fuentes & Atributos relacionados & Breve descripción \\
\hline $\begin{array}{l}\text { Leyenda de la } \\
\text { "Laguna de } \\
\text { Pomacochas" }\end{array}$ & $\begin{array}{l}\text { Bongará/ Gerald } \\
\text { Taylor } 1996\end{array}$ & $\begin{array}{l}\text { "diluvial" alteraciones } \\
\text { climáticas/laguna } \\
\text { hembra". }\end{array}$ & $\begin{array}{l}\text { "Laguna que se molesta y hierve, luego } \\
\text { hace llover intensamente, antes un } \\
\text { anciano avisa a un hombre y su hermana } \\
\text { para que se suban al cerro más alto y se } \\
\text { protejan" }\end{array}$ \\
\hline $\begin{array}{l}\text { Leyenda de la } \\
\text { "Laguna de } \\
\text { Mamacocha" }\end{array}$ & $\begin{array}{l}\text { Jalca Grande/ } \\
\text { Boletín "Kuelap" del } \\
\text { INC, N¹05, } 1994\end{array}$ & $\begin{array}{l}\text { "diluvial" alteraciones } \\
\text { climáticas/laguna } \\
\text { hembra" }\end{array}$ & $\begin{array}{l}\text { "La laguna de mamacocha, se molestaba y } \\
\text { hervía y comía animales, hombre y todo, } \\
\text { asi que un anciano aviso en el pueblo y } \\
\text { nadie lo creyó, pero una vieja y su hijo } \\
\text { se fueron a hacer su casa a la cordillera } \\
\text { y se salvaron cuando la laguna comió al } \\
\text { pueblo" }\end{array}$ \\
\hline $\begin{array}{l}\text { Leyenda “El } \\
\text { Haragán y la } \\
\text { Huacauilca" }\end{array}$ & $\begin{array}{l}\text { Jalca Grande/Gerald } \\
\text { Taylor } 2003\end{array}$ & "Riquezas" & $\begin{array}{l}\text { Describe al hombre Haragán que no } \\
\text { quería trabajar la tierra y para durmiendo, } \\
\text { otro hombre le quiso hacer una broma } \\
\text { con una serpiente colocándolo en el } \\
\text { cuello y esta se convirtió en oro ya que } \\
\text { era la Huacauillca. }\end{array}$ \\
\hline $\begin{array}{l}\text { Leyenda "La María } \\
\text { Uccha" }\end{array}$ & $\begin{array}{l}\text { Chachapoyas/ } \\
\text { Prof. Jamilton } \\
\text { Maldonado, } 2009\end{array}$ & "hambrunas y sequías" & $\begin{array}{l}\text { María Uccha encargó a su hijo con avispa } \\
\text { y este lloraba tanto que la avispa no pudo } \\
\text { cuidar tano que mama Uccha se enojó y } \\
\text { aplastó su cintura hasta volverse delgada, } \\
\text { por eso la avispa es así. }\end{array}$ \\
\hline $\begin{array}{l}\text { Leyenda "Mama } \\
\text { Cande" }\end{array}$ & $\begin{array}{l}\text { Chachapoyas/ } \\
\text { Prof. Jamilton Loja } \\
\text { Maldonado, } 2009\end{array}$ & "hambrunas y sequias" & $\begin{array}{l}\text { En febrero la gente preparaba el Chiclayo } \\
\text { carapa, si algún año era de escases la } \\
\text { Mama Grande se pasaba buscando sus } \\
\text { piojos y comiendo su usacho. }\end{array}$ \\
\hline $\begin{array}{l}\text { Leyenda de la } \\
\text { Mamayeya }\end{array}$ & $\begin{array}{l}\text { Chachapoyas/ } \\
\text { Prof. Jamilton } \\
\text { Maldonado, } 2009\end{array}$ & "hambrunas y sequias" & $\begin{array}{l}\text { Un hombre y una mujer tuvieron } \\
\text { varios hijos y en tiempos de hambruna } \\
\text { recordaban los buenos tiempos, asi que el } \\
\text { hombre y la mujer escondidos de sus hijos } \\
\text { empezaron a comer los granos de maíz } \\
\text { guardados pero los hijos los descubrieron, } \\
\text { en ese momento el hombre y mujer } \\
\text { llevaro a sus hijos a la montaña para que } \\
\text { aprendan a comer frutos, allí los dejaron } \\
\text { y con el tiempo se volvieron aves por que } \\
\text { no había nada de comer, los niños decían } \\
\text { mamayeya, plaga dios" }\end{array}$ \\
\hline
\end{tabular}

lleras, lugares de origen de lagunas y lugares de protección y nuevo habitad de los pueblos.

También está el elemento "comunidad", caracterizado por los poblados, los músicos, danzantes que incluso con nombre propio explican de sus orígenes, asi se comentan a los poblados de Pomacochas en Bongará, Colcamar en Luya, etc.

El elemento "hombre" que posee varios atributos, ya sea de género individual o confor- mado como pareja sea hombre/mujer o pareja Mujer/hermano y Padre/hija, donde incluso hay una relación de edades distintas.

También están conformando entre estas estructuras el elemento "héroe", caracterizado por "brujas", "brujos", "autoridades- líderes", viejos; está presente de manera sincrética la imagen de "dios"; también son figuras heroicas los "santos" "sacerdotes-obispos" como la imagen de Santo Toribio. 
Se integran además las imágenes de animales y describen plantas relacionada al entorno de las lagunas.

\section{Contexto espacial-temporal}

Hemos podido notar que estas imágenes ocupan un lugar y un tiempo, es decir se contextualizan en un espacio y un momento cronológico durante el proceso del relato, esto ha permitido ubicar los conceptos de arriba/abajo y derecha e izquierda de acuerdo a cada uno de los elementos que lo integran.

Este contexto espacial y temporal de los elementos nos permitimos ubicarlo teniendo en cuenta la estructura del pensamiento o cosmovisión Sur Andina ya que es la que ha sobrevivido hasta la fecha en los espacios ideológicos de Amazonas; siendo los atributos de Hanan pacha y Kay Pacha estos contextos.

En el caso de la distribución espacial de los elementos nos hemos permitido ubicar cada uno en su concepto estructural para poder establecer el orden y relaciones que existen entre estos de acuerdo al concepto pudiendo destacar que por ejemplo el elemento agua conecta- simbólicamente- tanto al Hanan pacha como al Kay pacha; es decir permanentemente el relato de alteración o de dinámica hidromorfa de manera simbólica recrea el atributo de movilidad; sin embargo este atributo posee un sustento ecológico e histórico social que podría encontrase mesclado entre los sucesos acaecidos en varios tiempos prehispánicos, pero también en tiempos del Incario y negados y re transformados por los Conquistadores Hispanos (Esquema 1).

En el caso de los demás elementos tales como: comunidad, hombre, héroe, animales y plantas, se ubican dentro del espacio de la estructura del Kay pacha, siendo entorno del narrador o relator y el que crea estos simbolismos, lo simboliza y mitifica cuando trasciende a su comunidad generacionalmente.

Considerando los estudios antropológicos sobre estructuras de la cosmovisión difundido por varios investigadores (T. Platt 1976; T. Zuidema y G. Urton 1976; E. Meyer 1977; Núñez del Prado 1979; E. Calero del Mar 2002) hemos optado por aplicar los conceptos de Yanantin y Misintin $^{10}$.

Estas concepciones estructurales se dan a una diversidad de atributos de género que se pueden identificar permanentemente en el discurso de los relatos y narraciones en las provincias del departamento de Amazonas, y que además de sus cualidades duales también están relacionadas a una constancia estructural de reciprocidad; siendo estas variables de identidad (E. Calero del Mar 2002).

El caso de la grafía Purum, el cual posee una estructura sui generis debe ser tomado como una unidad de cualidades diversas relacionado a aspectos de identidad que ahora más que nunca deben mirarse con mucho cuidado y deben definirse desde el aporte de los estudios arqueológicos, etnohistóricos y obviamente antropológicos.

La grafía Purum tiene una explicación y sustento mucho más amplio del que se ha considerado, si bien es cierto permite una explicación ligada al aspecto de identidades en el caso del sur andino y más aun como lo ha referido Viviana Manríquez (2002), refiriéndose a los pueblos chilenos-"El término "promaucaes" no reflejaría la construcción de un apelativo étnico dado a los indígenas, sino etnocategoría clasificatoria o un apelativo cultural que elaboró una exoidentidad sobre

10 Enrique Mayer (1977: 77), tomando el análisis de Tristán Platt, manifiesta que las cosas al reflejarse en un espejo son iguales una a otras y posee una relación $Y a-$ nantin, por ejemplo la mano izquierda y la derecha son iguales solamente en una relación de imagen de espejo. El marido y la mujer están también conceptualizados en una relación Yanantin. Núñez del Prado (1979: 5), asume que es el principio de oposición complementaria a través de la cual el hombre andino ve su universo y organiza su mundo en parejas de opuestos complementarios, todo lo que en él se encuentra. Estos opuestos complementarios son asociados a las nociones de "masculino y femenino", son interdependientes, jerarquizados y unidos entre sí por una cadena de intercambios recíprocos de diferente naturaleza o asimétricos.

Para Núñez del Prado (op. cit. 1979:5) dice que Masintin es el principio de identidad, solidaridad y equivalencia que establece el hombre andino entre los componentes de dos o más parejas de opuestos complementarios en base a cualidades o circunstancias comunes a ellos. 
Esquema 1: Distribución Espacial de los Elementos

\begin{tabular}{|l|l|l|l|l|l|l|}
\hline $\begin{array}{l}\text { Estructura } \\
\text { Cosmovisión }\end{array}$ & Agua & Comunidad & Hombre & Héroe & Animales & Plantas \\
\hline $\begin{array}{l}\text { HANAN PACHA } \\
\text { Cielo, Jalca- } \\
\text { Cordillera }\end{array}$ & $\begin{array}{l}\text { Lluvias, } \\
\text { Lagunas }\end{array}$ & & & & Eneas, totorales \\
\hline $\begin{array}{l}\text { KAY PACHA } \\
\text { Tierra, Agua, } \\
\text { subsuelo, Valles, } \\
\text { Temples }\end{array}$ & Lagunas & $\begin{array}{l}\text { Pomacochas } \\
\text { Colcamar }\end{array}$ & $\begin{array}{l}\text { Hombres y y } \\
\text { mujeres }\end{array}$ & $\begin{array}{l}\text { Brujas, } \\
\text { caciques, } \\
\text { Santos, } \\
\text { sacerdotes }\end{array}$ & $\begin{array}{l}\text { Caballos, } \\
\text { mulas, } \\
\text { toros, vacas }\end{array}$ & $\begin{array}{l}\text { Sauce, siogue, } \\
\text { carrizos, eneas }\end{array}$ \\
\hline
\end{tabular}

Esquema 2: Distribución especial de los elementos por Género

\begin{tabular}{|l|l|l|}
\hline Género & Yanantin & Misintin \\
\hline Varón & $\begin{array}{l}\text { Hombre/Mujer } \\
\text { Obispo } \\
\text { Padre/niña }\end{array}$ & Hombre/ hermano \\
\hline Mujer & $\begin{array}{l}\text { Bruja/Sr. Mallqui } \\
\text { Niña/Padre }\end{array}$ & Madre/hijas \\
\hline
\end{tabular}

estos indígenas, con el objetivo de homogenizar un panorama de identidades diversas y heterogéneas que operaban a nivel local o "microscópico" en la zona de estudio."(ibíd., 2002:337); sin embargo también es dinamizador a través de las figuras conceptuales del tiempo y del espacio enmarcada en el lenguaje de la estructura de Pachas.

\section{BREVES REFLEXIONES}

Nuestra interrogante de saber cuál es el origen de lo denominado Chachapoya (s) nos conduce a buscar diversos argumentos que nos permitan tener una mayor comprensión a cabalidad de la misma.

Sobre este particular, hemos revisado los sustentos del Dr. Waldemar Espinoza Soriano (1967) y la Dra. Inge Schjellerup (2005); cada uno de ellos han brindado una diversidad de argumentos sobre este término, todos sustentos historicistas generales de la región; sin embrago el análisis que hace el Dr. Zevallos Quiñones (1988; 1992), el cual observa una diversidad étnica en un territorio cuyos métodos de análisis e interpretaciones deben ser cada vez más coherentes y versátiles; con todo ello queda claro por parte de todos que la denominación de Chachapoya (s) fuera dado por los Incas, en ese sentido quedan interrogantes que hemos decidido reflexionar sobre las mismas y que pretendan determinar si lo Chachapoya(s) es una región?, una cultura de culturas?, o una categoría étnica?. Para responder todo ello es imprescindible que tanto la arqueología, la etnohistoria y la antropología de manera integral desempeñen una mayor comprensión y explicaciones al respecto, proponiendo métodos analíticos e interpretaciones valederas y modernas.

Al parecer hasta hoy no hemos concretado la visión desde distintas perspectivas de cómo observar y entender este vasto territorio, quizás uno de los últimos territorios donde las civilizaciones ancestrales tienen una historia propia y común, no muy bien observado por arqueólogos y otros científicos.

Por nuestro lado venimos identificando algunos trabajos de investigación que están reformulando desde una perspectiva estructural basado en categorías culturales, las cuales vienen identificando variables que pueden llegar a ser medibles entorno a la problemática de identidad, en ese sentido la antropóloga Viviana Manríquez ha publicado en el Boletín de la PUCP, luego del extenso debate y seminario sobre Identidades y transformación en el Tahuantinsuyo $y$ en los andes coloniales. Perspectivas arqueológi- 
cas y etnohistóricas llevado a cabo el año 2002, proponiendo que la historia del pueblo chileno desde la región de los Promaucaes habría sido denominada con la categoría de Purumaucas como lo refieren algunos historiógrafos de la Colonia como el Inca Garcilaso de la Vega. La investigadora Manríquez sustenta que al parecer se trataría de una etnocategoría a manera de identidad "microscópica" y que sigue transitando entre los pueblos de indios (V. Manríquez 2002: 350).

Desde el punto de vista del análisis estructural etnolingüístico, en el caso del término Chachapoya o Chacha/puya creemos que podría constituir una subcategoría de identidad, relacionada a varios aspectos de la categoría Purum, y, que fuera transferida por los Incas, consecuentemente tomada por los españoles.

En ese sentido hemos revisado desde la perspectiva lingüística las grafías Chacha/puya y Purum; pudiendo identificar que en varios diccionarios se relaciona a un origen foráneo del ámbito de la región nororiental del marañón, precisamente esta vinculada a una serie de explicaciones de origen Aymara y Quechua; asi se nos ha ocurrido separar la grafía Chacha de la grafía Puya, en la que, la primera está referido a la polisemia de "hombre" u "hombres"-para verlo desde el contexto andino peruano: persona(s) $\mathrm{u}$ individuo(s) en comunidad. También referida a la acepción biológica de hombre varón.

En el caso de la grafía Puya decimos que esta no es local siendo también de origen Aymara, tampoco es Quechua; y, aunque pudiera tener una similitud gráfica cuando escribimos en castellano la palabra Puy, pues esta no es asi; Puya es traducido como "mazorca de maíz seco" y que en el ande sureño todavía las comunidades cusqueñas y puneñas siguen realizando una diversidad de actividades agrícolas y festivas relacionadas a ella y que en el caso de algunas comunidades campesinas del departamento de Amazonas como es la Jalca Grande, Santo Tomás, Kuelap, María en el valle del Utcubamba desarrollan la fiesta de la Kutipa o fiesta de la deshierba del maíz, llevados a cabo entre los meses de Diciembre hasta el mes de Marzo, donde las danzas de las benllas y las pallas agradecen a la "mama pacha" por el maíz; asi, se preparan panes, Guaguas, tamales, humi- tas, etc.; donde hombres y mujeres peregnizan su unidad, aquella que señala y reafirma la vida en comunidad y que la simbolización de Yanantin y Misintin dinamizan y comunican.

Podríamos proponer que lo Chachapuya sería definido entonces como aquellas personas de una comunidad que están relacionadas a una actividad específica, en este caso ligado al conocimiento del sembrado y preparación del maíz, esto permite observar que no necesariamente sería una cultura desde una perspectiva distinta a la historicista y genérica, si no estaría especificando una categoría de identidad refiriéndose a una característica de etnicidad, que habría desarrollado esta actividad en un ámbito territorial cuyas características dinámicas y ambientales así lo permitieron y las que fueron recreadas; precisamente fue el Incario que diera esa denominación a la gente local en las zonas donde cohabitaron. Los Incas estarían catalogando una nueva identidad al grupo o los grupos que habitaron los parajes de las actuales provincias de Chachapoyas, Luya, Bongará y Rodríguez de Mendoza como tales, de acuerdo a restructuraciones étnicas en común, lo que habría significado la nueva denominación: Chachapoya(s), consecuentemente los Hispanos han mantenido dicho proceso y estructura, lo cual ha hecho que algunos estudiosos vean estas cualidades homogenizadas no solo de manera planificada sino simbólica dada por el Incario; todo ello ha permitido que Chachapoyas sea más una cualidad de cultura desde una perspectiva interpretativa historicista euro-americano.

En el caso de la grafía Purun o Puruma siendo en quechua como en algunos casos en Aymara, hemos observado que varios historiógrafos e investigadores han determinado que posee varias acepciones (espacial, de lugar, de distinción cultural, distinción social, política y religiosa), incluso hemos descrito a tres sitios arqueológicos o otros espacios arqueológicos que son identificados con el término Purum Llacta y además el término de Purummachu que hasta el día de hoy la gente de las poblaciones rurales lo sigue catalogando todo aquello referido a la gente antigua, es decir es una etnocategoria distintiva de identidad. 
En ambos casos tanto Chacha/puya como Purum se distinguen por ser categorías que permiten caracterizar la etnicidad de los grupos reorganizados por los Incas, uno en términos de reorganización y el otro como simbolismo de su semiótica, esto llevó indefinidamente a darle el nuevo carácter estructural sobre las organizaciones locales desde todo sentido, acción que fuera dado en su largo proceso de más de 55 años hasta la llega de las huestes Hispanas.

En el caso de Purum en la región de las provincias de Chachapoyas, Luya, Bongará y Rodríguez de Mendoza, existe una marcada tradición oral referida a una de las cualidades del simbolismo hidromorfo ${ }^{11}$; expone en gran mayoría la explicación de la transformación del paisaje y de grupos humanos, recreados a partir del simbolismo estructural referida al "agua" y su figura dinamizadora he venido sosteniendo en un artículo precedente (R. Barcellos 2011a). En todo caso el papel simbólico que al "agua" se le da para explicar dinámicas, cambios y transformaciones, podemos decir que es el contexto ideológico de este precepto.

\section{CONCLUSIONES PRELIMINARES}

Las conclusiones preliminares que asumimos en este artículo referido al conocimiento y búsqueda de la comprensión sobre el origen y explicación de este proceso cultural civilizatorio al cual hasta ahora la gran mayoría de estudiosos se refiere a ello de manera general como los

11 Asumimos que las sociedades ancestrales debido a la trascendencia de la relación hombres- naturaleza o medio, existen elementos que son fundamentales en esa relación, uno de estos elementos es el rol y papel del "agua" interpretada y comunicada de manera simbólica por casi todas las sociedades del mundo, no solo ocupa un sitial - al que osaré denominar "primogénico" sino fundamentalmente vital en la vida social, económica, tecnológica e ideológica de las sociedades ancestrales.

El simbolismo hidromorfo, no es más que la expresión de la relación hombre- naturaleza y que posee una base fundamentalmente de origen, esta es estructurada de diversas formas y conceptos de acuerdo a cada grupo o proceso cultural. En el caso de las sociedades ancestrales tardías en Amazonas, no escapan a las identificadas en las demás sociedades ancestrales del mundo andino.
Chachapoya(s) consideramos deberemos observar que:

1. Chachapoya y Purum tiene una relación desde el punto de vista estructural ya sea desde la figura etnolingüística como parte de su etnicidad, ambos comunican que se tratan de categorías de identidad, que explicarían las nuevas designaciones que recibieron los grupos o grupo conquistado por los Incas; con ello queremos resaltar la grafía Kulungus que podría estar relacionada a un tipo de categoría de identidad.

2. Purum también está comunicando desde la perspectiva estructural la simbolización de un viejo mito cuyo ámbito sobre pasa su solo presencia en la región, éste está ligado a la explicación a través de la cosmovisión del "agua" y que vengo postulando en denominar la estructura hidromorfa, siendo uno de los elementos y principios de toda una concepción de la simbolización de lo dinámico ampliamente marcado en casi todas las geografías y procesos culturales de lo que fuera el Tahuantinsuyo.

3. La denominación de Chachapoya y Purum se encuentran relacionadas en estructura y en distribución territorial, aspectos que vinculan un momento de trascendencia del Incario en los territorios locales.

4. Puya en su traducción relacionado al cultígeno del maíz ${ }^{12}$ y su manejo, expresado

$12 \mathrm{El}$ año 2002 y 2003 dirigimos las primeras investigaciones arqueológicas en el sitio de Purum llacta ubicado en el actual distrito de San Juan de Cheto, provincia de Chachapoyas; las excavaciones de las 7 unidades residenciales de planta circular y rectangular mostraron la presencia de una diversidad de artefactos y herramientas, siendo la estructura de planta rectangular $\mathrm{N}^{\circ} 12$ estudiada por los colegas Jhonny Siccha García, Esteban García y Karina Reyes los que identificaron la mayor cantidad de instrumentos en piedra: manos de moler o "morjones", batanes, azadas o azadones, asociado a basurales donde se han identificado variedades de corontas y en algunos casos maíces en mazorcas entre otras semillas no identificadas; además de una relación espacial y funcional a sectores arqueológicos ligados a terrazas agrícolas y andenes han permitido que asumamos que el sitio arqueológico tuvo un papel preponderante en el manejo, control, y tecnología sobre el conocimiento del mejoramiento de cultígenos agrícolas como el maíz" (Barcellos 2004). 
como actividad no solo agrícola sino como acción que ha conectado la religiosidad auténtica de los ancestrales pueblos; además permite entender que también se trataría de una categoría étnico - organizativo con respecto a identificar socioculturalmente grupos o grupo de poblados dedicados al conocimiento del maíz.

Finalmente debo mencionar que mas allá de coincidir con Weiss y Middendorf sobre el origen lingüístico Aymara de la denotación Chachapoya, en el presente artículo debo proponer un mayor análisis del mismo desde una perspectiva estructural del Lenguaje pero observada y entendida desde las bases y fundamentaos conceptuales andino y nor amazónicas. No debería vérsele como una Cultura en términos generales, sino como uno de los rasgo étnico otorgados por los Incas y que estructura su nueva identidad.

Con ello es fundamental el aporte de la arqueología desde observaciones y aplicaciones metodológicas en el que las variables cronológicas no puedan ser tratadas de la misma manera que se tratan los vestigios de los demás contextos andinos y costeños, en todo caso se requiere una arqueología con diseños metodológicos propios y que a partir de ello se integren en la comprensión de su posición en la trascendencia andino- nor amazónico.

\section{BiBLIOGRAFÍA}

Albornóz, Cristóbal

1967 [1570] "Un inédito de Cristóbal de Albornoz: La Instrucción para descubrir todas las Guacas del Pirú y sus camayos y Haziendas". En Duviols, Pierre (Ed.) Journal de la Societé des Americanistes, vol. 56, n 1, 7-39. París.

Bertonio, Ludovico

1984 [1612] Vocabulario de la lengua aymara, edición fascimilar. Ediciones CERES/IFEA/ MUCEF. Tomo II, Cochabamba- Bolivia.

Calancha, Antonio de

1638 Corónica moralizada del origen de San Agustín en el Perú con sucesos egenplaros desta Monarquia. Barcelona.
Cáceres, Efraín

2002 El Juicio del Agua- "Unu Huishu": Simbolismo y significado ecológico del agua en mitos andinos. El milagro de la laguna salada" de Musuq Llaqta. Primera Edición Abya-Yala, p. 173. Quito-Ecuador.

Calero del Mar

2001 Le monde préhispanique andin dans la genèse de l'oeuvre romanesque de José María Arguedas. Thèse de Doctorat d'Université, Université de Paris X Nanterre, $427 \mathrm{p}$.

Cieza de León, Pedro

1995 [1553] Crónica del Perú. Primera Parte. 229-231, Tercera Edición. Lima: Fondo Editorial de la Pontificia Universidad Católica del Perú, Academia Nacional de Historia.

Cobo, Bernabé

1964 [1653] Historia del Nuevo Mundo. En Obras del padre Bernabé Cobo, Tomo 161. Biblioteca de Autores Españoles XCIXCII, Atlas, Madrid- España.

Church, Warren, Thomas Lenon y Miguel Cornejo García

1989 "Investigaciones arqueológicas en el Parque Nacional Río Abiseo, San Martín”. En Boletín de Lima, 62: 43-56. Lima Perú.

Duviols, Pierre

1986 "Un inédito de Cristóbal de Albornoz: La Instrucción para descubrir Todas las Guacas del Pirú y sus camayos y haziendas". Journal de la Societé des Americanistés de Paris. T. LVI-1. París 1967, p. 33. Cultura andina y represión : procesos y visitas de idolatrías y hechicerías. Cajatambo siglo 16. Cusco.

Espinoza, Waldemar

1967 "Los Señoríos étnicos de Chachapoyas y la alianza hispano-chacha". En Revista Histórica, XXX: 224-333.

Garcilaso de la Vega, Inca

1967 [1609] Comentarios Reales de los Incas. 4 vols. Lima: Universidad Nacional Mayor de San Marcos. 
Gonzales Holguín, D.

1952 [1608] Vocabulario de la lengua de todo el Peru llamada lengua qquichua o del inca (prologo de Raúl Porra Barrenechea), Lima: UNMSM.

Guaman Poma de Ayala

1993 [1616] Nueva Corónica y buen gobierno (edición y prólogo de F. Pease G.-Y; vocabulario y traducciones de J. Szemiñski), 3 vol. Lima: Fondo de Cultura Económica.

Guillén, Sonia

1999 "Proyecto Arqueología de Emergencia: Inventario, Catalogación y Conservación de los Materiales Arqueológicos de los Mausoleos de la Laguna de los Cóndores". Informe Final Volumen I. Lima Perú

2003 "De Chinchorro a Chiribaya: Los ancestros de los Mallquis Chachapoya- Inca". pp: 287-303 En Boletín de Arqueología PUCP, 7: 435. Lima, Perú.

Horkheimer, Hans

1958 Algunas consideraciones acerca de la Arqueología en el valle del Utcubamba. En Actas y Trabajos del II Congreso Nacional de Historia del Perú, I: 71-101. Lima.

Huertas, Lorenzo

1990 Los Chancas Procesos disturbativo en los Andes. En Historia y Cultura 20: 11 48; Revista del Museo Nacional de Historia INC- Lima.

Kauffmann, Federico

2003 Chachapoya (s) moradores ancestrales de los Andes Amazónicos peruanos. Fondo Editorial de la Universidad Privada Alas Peruanas

Lerche, Peter Thomas

1992 Los chachapoya y los símbolos de su historia. Lima: s/e.

Leviller, R.

1920 [1583-1600] Probanzas y méritos y servicios de los gobernantes. Documentos del Archivo de Indias. Tomo II, Rivadeneyra, Madrid.
Malengreau, Jaques

1995 "Trashumancia, Migraciones y Restructuraciones Étnicas Sierra y Selva al Norte de Chachapoyas (Perú)". En Boletín del Instituto Francés de Estudios AndinosIFEA. 24: 295-315. Lima.

2009 "Parientes, paisanos y ciudadanos en los Andes de Chachapoyas- Identidades, divisiones y solidaridad en la comunidad de San Carlos". Edición en castellano por el Centro de Estudios Regionales Andinos Bartolomé de Las casas- CBC y en la Revista de Antropología 15 del Instituto Francés de Estudios Andinos. Lima- Perú.

Manriquez, Viviana

2002 "Purum Aucca, Promaucaes: de significados, identidades y etnocategorias. Chile Central, siglos XVI-XVIII". En Boletín de Arqueología PUCP 6: 337 354. Pontificia Universidad Católica del Perú.

Mayer, Enrique

1977 "Andean Kinship and Marriage". En American Anthropological Association, 7: 60-80; Washington D.C.

Middendorf, Ernst Wilhel

1970 [1882] Gramática Keshua, traducción del alemán de E. More, Lima.

Morales Gamarra, Ricardo, Luis Valle y Warren Church

2002 "Los Pinchudos: Un estudio preliminar de su población”. En Sian 8(12):1-41. Trujillo- Perú.

Narváez, Luis Alfredo

1988 "Kuelap, una ciudad fortificada en los Andes Nor-Orientales de Amazonas, Perú”. En Simposium: Arquitectura y Arqueología. Pasado y futuro de la construcción en el Perú. pp: 115-142, Universidad de Chiclayo, Chiclayo Perú.

1996 "La Fortaleza de Kuelap". En Arkinka, 2, 13. Revista de Arquitectura, Diseño y Construcción, Lima.

1999 Proyecto de Puesta en Valor de la Fortaleza de Kuelap. Primer Informe. Convenio INC- Concejo Transitorio Regional Amazonas. 
2000 Proyecto de Puesta en Valor de la Fortaleza de Kuelap. Primer Informe. Convenio INC- Concejo Transitorio Regional Amazonas.

2004 Investigación, Conservación y Acondicionamiento Turístico de la Fortaleza de Kuelap. Informe Final. Convenio MINCETUR - COPESCO - Gobierno Regional de Amazonas - INC.

Nystrom, Kennth

2005 The Biological and Social Consequences of Inca Conquest of the Chachapoya region of Northern Peru. PhD dissertation, University of New Mexico, Albuquerque.

Nystrom, Kennth; A. Goff y M. Goff

2005 "Mortuary behavior reconstruction through paleoentomology: A case study from Chachapoya, Perú". En International Journal of Osteoarchaeology 15(3):175-185.

Nuñez del Prado, Daisy

1979 "Yanantin: la dualidad andina”, En Simposium Ideología y Sociedad en los Andes, IV Congreso del Hombre y la Cultura Andina. Cusco.

Platt, Tristan

1976 Espejo y Maíz: Temas de la estructura Simbólica Andina. Editado Cuadernos de investigación CIPCA. La Paz- Bolivia.

Reichlen, Henry

1950 "Recherches Archaelogiques dans les Andes du Haut Utcubamba”. En Journal de la Societé des Americanistes. Nouvelli série. Tome XXXIX. París.

Ruiz Estrada, Arturo

1972 La alfarería de Kuélap: Tradición y Cambio. Tésis de Bachiller. Universidad Nacional Mayor de San Marcos.

2010 Amazonas: arqueología e historia. Lima: Fondo Editorial de la Universidad Privada Alas Peruanas.

Ruíz Barcellos, Jorge Luis

2001 Recuperación histórica del complejo arqueológico Purum Llacta, distrito de Cheto, departamento de Amazonas. Informe de Investigación Arqueológica-Primera Temporada. Chachapoyas. 2004; 2005; 2006.
2002-2003 Excavaciones Arqueológicas en los Sectores el Quemado y Monte Peruvian del complejo Arqueológico Purum Llacta, Distrito de Cheto- Departamento de Amazonas. Informe de campo-Segunda Temporada. Chachapoyas.

2004 "Purum Llacta: Centro poblado Chachapoya dedicado a la agricultura". En Sian, Revista Arqueológica, 9: 10-11, Edición № 15, Abril.

2006 Investigación, Conservación y Acondicionamiento Turístico del sitio arqueológico de Yálape-Levanto I Etapa. Informe de Campo. Convenio MINCETUR- Gobierno Regional Amazonas- INC.

2007 "Arqueología y Arquitectura de Yálape en la Provincia de Chachapoyas, Departamento de Amazonas". En ARKINKA 136: 84-91. Marzo. Lima.

2010 "Simbolización de la Vida y la Muerte en el arte rupestre de Cocachimba de Bongará y los petroglifos de Mátala- Maripata en Chachapoyas, departamento de Amazonas". Elaborado y presentado al Boletín de Lima para su publicación el año 2011-Oct.

Ruiz Barcellos, Jorge y Oliver Fabre

2004 Prospecciones arqueológicas en la mini cuenca del río Olia, departamento de Amazonas. Informe de campo, INC Chachapoyas, 55 págs.

Sanchez, Sandra

1996 Fragmentos de un tiempo largo. Tilcara entre los siglos XVI y XIX. Tésis de Licenciatura inédita, Facultad de Humanidades y Ciencias Sociales; Universidad nacional de Jujuy. Jujuy.

Schjellerup, Inge R.

1976 "Problems in the Etnohistory of Uchucmarca". En Actes du XLIIe Congrés International des Américanistes, vol. IXB,pp.221-232.

2005 Incas y españoles en la conquista de los Chachapoya. Fondo editorial de la Pontificia universidad Católica del Perú y el Instituto Francés de Estudios AndinosIFEA. $641 \mathrm{p}$. 
Schjellerup, Inge R. et al.

1986-1987 "Cazadores de cabezas en sitios PreInca de Chachapoyas, Amazonas". En Revista del Museo Nacional de Lima. T. XLVIII: 135-185. Lima Perú.

Shady Solis, Ruth

1972 La arqueología de la cuenca inferior del Utcubamba. Tésis de Doctarado. Universidad Nacional Mayor de San Marcos. Lima.

Taylor, Gerald

1975 "La distribución del habla Quechua". Seminario La voz de Amazonas, año XXIII, 580, Chachapoyas 21 de diciembre.

1996 Tradición oral quechua de Chachapoyas. Lima. IFEA.

2000 Estudios Lingüísticos sobre Chachapoyas. Lima. Fondo Editorial de la UNMSM, IFEA.

2003 Relatos quechuas de la Jalca Grande. IFEA. Lluvia Editores. Lima.

Torero, Alfredo

1964 "Dialectos quechuas". En Anales Científicos de la Universidad Agraria, v. II, $\mathrm{N}^{\circ} 4$. Lima.
Weiss, Pedro

1949 "Estudio sobre los lamistas -su grupo sanguíneo- algunas pruebas psicotécnicas". En Revista del Museo Nacional, t. XVIII, Lima.

Zevallos Quiñones, Jorge

1987 "Introducción a la etnohistoria de Chachapoyas". En Kuelap, Boletín del INC/ Amazonas.

1995 "El Área geográfico-cultural de la Prehistoria de Chachapoyas. Una nueva postulación" En Gaceta Arqueológica Andina. 24: 13-23, Vol. VII, del Instituto Andino de Estudios Arqueológicos, edit. Epígrafe S.A. Lima.

Zuidema, T. y G. Urton

1976 "Constelación de la Llama en los Andes Peruanos". En Allapanchis 9: 59-119; edición IPA- Cusco. 